\title{
Ground-penetrating radar observations of enhanced biological activity in a sandbox reactor
}

\author{
P. C. Schillig, ${ }^{1}$ G. P. Tsoflias, ${ }^{1}$ J. A. Roberts, ${ }^{1}$ E. M. Patterson, ${ }^{1}$ and J. F. Devlin ${ }^{1}$ \\ Received 7 September 2009; revised 10 February 2010; accepted 1 March 2010; published 27 July 2010.
}

[1] In this study, we evaluate the use of ground-penetrating radar (GPR) to investigate the effects of bacterial activity in water saturated sand. A 90-day laboratory-scale controlled experiment was conducted in a flow-through polycarbonate sandbox using groundwater from the Kansas River alluvial aquifer as inoculum. After 40 days of collecting baseline data, bacterial growth was stimulated in the sandbox by the addition of a carbon and nutrient solution on a weekly basis. Radar signal travel time and attenuation were shown to increase downgradient of the nutrient release wells relative to upgradient locations.

After 60 days, the frequency of nutrient injections was increased to twice per week, after which gaseous bubbles were visually observed downgradient of the nutrient release wells. Visual observation of active gas production correlated spatially and temporally with a rapid decrease in radar signal travel time, confirming that GPR can monitor the generation of biogenic gases in this system. Analysis of the sediments indicated microbial lipid biomass increased by approximately one order of magnitude and there were no changes in the inorganic carbon content of bulk sediment mineralogy. These findings suggest that the increase in biomass and gas production may be responsible for the observed changes in radar signal travel time reported in this study. Therefore, this study provides evidence that GPR can be used to monitor biological activity in water saturated sand.

Citation: Schillig, P. C., G. P. Tsoflias, J. A. Roberts, E. M. Patterson, and J. F. Devlin (2010), Ground-penetrating radar observations of enhanced biological activity in a sandbox reactor, J. Geophys. Res., 115, G00G10, doi:10.1029/2009JG001151.

\section{Introduction}

[2] Bioremediation and natural attenuation are widely used methods for removing contaminants from the subsurface. For effective contaminant removal, both approaches rely on the development of an enhanced bioactive zone relative to the surrounding area. Zones of enhanced biological activity can cause changes to the bulk petrophysical and pore water properties of a saturated porous medium, for example, by the production of cells [Baveye et al., 1998], extracellular polysaccharides [Vandevivere and Baveye, 1992a], biogenic gases [Delozada et al., 1994], secondary minerals [Williams et al., 2005; DeJong et al., 2006], inorganic and organic acids that lead to mineral dissolution [Welch et al., 2002], and redox processes that dissolve or precipitate minerals [RinckPfeiffer et al., 2000]. Recently, investigators began studying the responses of geophysical methods applied to sediments in which biological activity was enhanced by the presence of a growth nutrient. The use of geophysical techniques to investigate biological activity has formed a new field of study called biogeophysics. Biogeophysical studies have shown that enhanced biological activity in hydrocarbon contaminated sediments cause increased pore water conductivity (due to \footnotetext{
USA.

Copyright 2010 by the American Geophysical Union. 0148-0227/10/2009JG001151
}

Department of Geology, University of Kansas, Lawrence, Kansas, mineral dissolution) and increased bulk electrical conductivities (due to mineral dissolution and possibly surface conduction) [Sauck, 2000; Cassidy et al., 2001; Atekwana et al., 2004a, 2004b]. Building upon these results, other laboratory studies provided evidence that supports a more complex conceptual model in which the interfacial electrical properties of porous media are altered due to cell attachment and biofilm formation [Ntarlagiannis et al., 2005; Abdel Aal et al., 2006, 2009].

[3] By suspending cells in a fluid medium, their passive electrical properties can be isolated from the earth environment and characterized by examining the suspension's frequency dependent dielectric behavior. Methods such as dielectric spectroscopy and dielectrophoresis have demonstrated that by examining the frequency dependant dielectric response of cell suspensions, information regarding cell morphology [Bone et al., 1996], cell wall characteristics (e.g., Gram stain [Sanchis et al., 2007]), viability and biomass [e.g., Patel and Markx, 2008] can be ascertained. The contrast between the dielectric constant of cell suspensions and that of the surrounding fluid has been shown to be frequency dependent, where with increasing frequency the dielectric constant of the cells decreases, approaching that of the suspending fluid [Carstensen, 1967; Asami et al., 1980; Prodan et al., 2004]. This phenomenon is thought to occur as a result of numerous dispersions caused by the dielectric properties of membranes (MHz range), the relaxation of biopolymers and bound water ( $\mathrm{MHz}$ to $\mathrm{GHz}$ range), and reorientation 
of water and other molecules ( $>1 \mathrm{GHz})$ [Miller et al., 2005]. In the frequency range of ground-penetrating radar (GPR) (MHz to GHz), dielectric spectroscopy studies of cell suspensions show that small increases in dielectric constant relative to the suspending fluid can be measured [Carstensen, 1967; Asami et al., 1980]. These studies provide encouraging indications that high frequency electromagnetic (EM) methods such as GPR may be capable of detecting changes in cell concentration in porous media. If so, it is expected that only small changes in EM wave velocity of propagation and resulting travel time would be observed from the anticipated small increase in dielectric constant.

[4] Previous studies show that GPR has been used in the field successfully to characterize biological activity. Field GPR observations have provided evidence relating increases and decreases in dielectric constant to changes in volumetric water content (i.e., saturation porosity) due to the dissolution, and downgradient reprecipitation of calcite, respectively. Such was the case for a $\mathrm{Cr}(\mathrm{VI})$ contaminated aquifer subjected to hydrogen release compound treatments to stimulate microbial activity [Hubbard et al., 2008]. Mineral dissolution was also inferred on the basis of GPR measurements at the field scale. Increases in electrical conductivity, primarily attributed to an increase in dissolved ionic constituents during biodegradation of light nonaqueous phase liquids (LNAPL), were shown to increase GPR wave attenuation [Sauck et al., 1998; Bradford, 2007; Cassidy, 2007]. Similarly, in a biostimulation experiment with vegetable oil emulsion, borehole GPR amplitude observations, together with electrical logs, were used to track spatial and temporal changes in pore water electrical conductivity, which resulted in GPR wave attenuation further downgradient than the injected emulsion [Lane et al., 2006]. In a multiyear field monitoring study, decreases in pore water electrical conductivity and mass removal of hydrocarbon in a LNAPL contaminated aquifer was suggested as a possible explanation for increased signal strength from GPR reflections [Che-Alota et al., 2009]. In another study, biogenic $\mathrm{CH}_{4}$ and $\mathrm{CO}_{2}$ gas distributions in peatlands were mapped by interpreting surface and borehole GPR responses with direct gas and soil moisture probe data [Comas et al., 2005]. The authors presented evidence suggesting that zones of relatively low reflectivity, identified by surface GPR, were correlated with the accumulation of biogenic gas. Anomalously high EM wave velocities, as measured by borehole GPR, were attributed to a decrease in dielectric constant caused by up to a $10 \%$ loss in saturation. Both zones of high EM wave velocities and low reflectivity were correlated with high $\mathrm{CH}_{4}$ and $\mathrm{CO}_{2}$ gas production [Comas et al., 2005].

[5] Previous field studies show that GPR can be used to detect the products of microbial activity in the subsurface, such as changes in bulk electrical conductivity, mineral dissolution and precipitation, and the formation of biogenic gas. Laboratory studies indicate that the dielectric constant of cell suspensions is frequency dependent and generally different than that of the suspending fluid. However, there remains a need to determine if GPR is a viable method for investigating the effects of microbial activity and accompanying changes in an earth environment. The purpose of this study is to investigate spatial and temporal changes in GPR signal travel time and amplitude associated with enhanced biological activity in water-saturated sand. The results from this study provide novel insights regarding radar wave response to biostimulated, saturated, granular porous media.

\section{Methods}

\subsection{Reactor Construction and Setup}

[6] A flow-through tank packed with sand, hereafter referred to as the sandbox, was subjected to time-lapse GPR reflection to monitor electromagnetic wave two-way travel time and amplitude changes during biostimulation. The sandbox measured $1.0 \mathrm{~m} \times 1.0 \mathrm{~m} \times 0.3 \mathrm{~m}$ and was constructed of $12.7 \mathrm{~mm}$ (0.5 inch) thick sheets of polycarbonate (Figure 1). Two screens, constructed from a composite frame and $200 \mu \mathrm{m}$ Nytex mesh, established the upgradient and downgradient ends of the sand filled portion of the tank, creating open water reservoirs at the two ends of the tank. This design made it possible to maintain a uniform hydraulic gradient across the water saturated sand. Three fully screened wells positioned halfway down the long axis of the tank (between gridlines 3 and 4 in Figure 1) were used for the injection of a nutrient solution to stimulate microbial growth in the downgradient section of the tank, whereas microbial growth was not actively stimulated in the upgradient section. Two $0.5 \mathrm{~cm}$ diameter high-density polyethylene monitors, placed in the center of each of the upgradient and downgradient sections, allowed for the collection of aqueous samples. Prior to the addition of sand, all internal sandbox components were rinsed with deionized water and cold-sterilized with $100 \%$ methanol. Both downgradient and upgradient sections of the sandbox were imaged by 21-point GPR reflection grids on the side of the tank (Figure 1). An aluminum sheet was placed on the side of the sandbox opposite the grid, to serve as a reflector for transmitted GPR energy. Fine-grained silica sand (Quickcrete ${ }^{\circledR}$ No. 1961) was dry-sterilized at $400^{\circ} \mathrm{C}$ for $8 \mathrm{~h}$ and wet packed with deionized water. Native groundwater was acquired from an oligotrophic, uncontaminated portion of the Kansas River alluvial aquifer [McVey, 2000] and served as an inoculum. The groundwater has been characterized as circum-neutral in $\mathrm{pH}$ (6.9-7.4), with a mean pore water electrical conductivity (EC) of $628 \mu \mathrm{S} \mathrm{cm}^{-1}$. Oxygen, nitrate and sulfate are available as terminal electron acceptors (TEAs). However, sulfate is the dominant TEA with concentrations of about $35 \mathrm{mg} \mathrm{L}^{-1}$ [McElwee et al., 1995]. The groundwater inoculum was supplied to the tank from a Mariotte assembly, and allowed to flow through the sand with a constant flow rate of $\sim 7 \mathrm{~mL}$ $\min ^{-1}$. The sandbox was monitored for 39 days before the injection of any nutrient solutions, to establish background conditions. Microbial growth was stimulated on day 40 with an autoclaved nutrient solution containing $10 \mathrm{~g}$ of Tryptic Soy Broth (TSB) and $10 \mathrm{~g}$ of sodium acetate, dissolved in one liter of deionized water and diluted to three liters. As an all purpose medium, TSB contains $57 \%$ pancreatic digest of casein, $10 \%$ papaic digest of soybean meal, $17 \% \mathrm{NaCl}$, $8 \%$ dipotassium phosphate, and $8 \%$ dextrose. The acetate was supplied as a carbon source associated with stimulated denitrification and sulfate reduction [Devlin and Barker, 1996; Gierczak et al., 2007]. The electrical conductivity of the diluted nutrient solution at the time of injection was $3850 \mu \mathrm{S} \mathrm{cm}^{-1}$. Between days 40 and 60, the nutrient solution was injected once per week. After day 60, nutrient injections increased to twice per week. The experiment ran for a total of 90 days. 


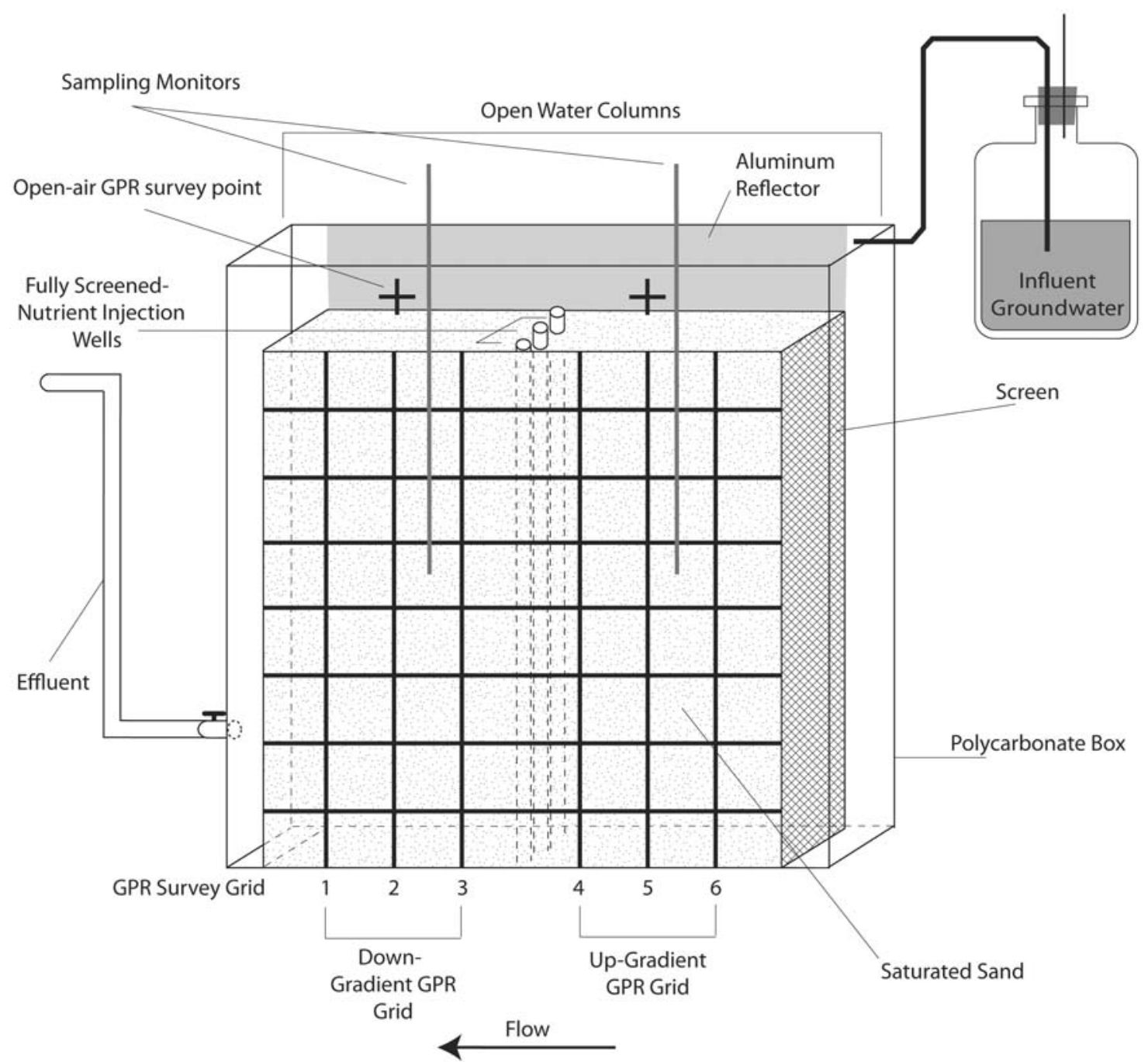

Figure 1. Schematic of the flow-through tank, or sandbox, showing the GPR data acquisition grids along with the location of the injection wells and sampling ports.

\subsection{Geochemical Sampling and Biomass Analysis}

[7] Aqueous samples were collected daily from the monitors in both the upgradient and downgradient locations. Samples of pore water $(100 \mathrm{~mL})$ were analyzed for EC, $\mathrm{pH}$, and temperature twice daily. Electrical conductivity was measured using an Accumet AP75 conductivity Data Meter that was calibrated with $12.88 \mathrm{mS}$ and $1413 \mu \mathrm{S}$ solutions of $\mathrm{KCl}$ at $25^{\circ} \mathrm{C}$. The $\mathrm{pH}$ meter was calibrated prior to each use with three-point calibration lines $(\mathrm{pH}=4,7$, and 10$)$. At the completion of the experiment (day 90), three cores were collected from two locations downgradient and one location upgradient of the nutrient injection wells, to assess biomass growth. Core material was recovered to a depth of 40 to $50 \mathrm{~cm}$ below the sand surface in the tank. The cores were sectioned at $10 \mathrm{~cm}$ intervals and freeze-dried in preparation for total lipid biomass analysis. Phospholipids were extracted by delivering $2.0 \mathrm{~g}$ of sediment into a single-phase solution containing $7.5 \mathrm{~mL} \mathrm{CHCl}_{3}, 15.0 \mathrm{~mL} \mathrm{CH}_{3} \mathrm{OH}$, and $5.0 \mathrm{~mL}$ of $50 \mathrm{mM}$ phosphate buffer. The single-phase solution was split into two phases by adding $7.5 \mathrm{~mL}$ deionized water and $7.5 \mathrm{~mL}$ of $\mathrm{CHCl}_{3}$ to remove the $\mathrm{CH}_{3} \mathrm{OH}$ and concentrate the phospholipids in the $\mathrm{CHCl}_{3}$ phase. The phospholipids containing $\mathrm{CHCl}_{3}$ phase was withdrawn, passed through a $\mathrm{NaSO}_{4}$ glass-fiber filter to remove particulate and water, and evaporated in a $37^{\circ} \mathrm{C}$ water-bath to concentrate the phospholipids. Concurrently, orthophosphate standards $(0 \mathrm{nM}, 1.5 \mathrm{nM}$, $3 \mathrm{nM}, 6 \mathrm{nM}, 10 \mathrm{nM}$, and $15 \mathrm{nM}$ ) made from glycerol phosphate were processed in duplicate with samples. The samples and standards were then digested by combining the extracted/prepared phospholipids with $2.0 \mathrm{~mL}$ potassium persulfate $(5 \mathrm{~g} \mathrm{~K}$-persulfate in $99 \mathrm{mLs}$ deionized water and $1 \mathrm{~mL} 0.36 \mathrm{~N} \mathrm{H}_{2} \mathrm{SO}_{4}$.) and reacted at $95^{\circ} \mathrm{C}$ overnight. In preparation for analysis, samples and standards were combined with $0.5 \mathrm{~mL}$ ammonium molybdate $\left(2.5 \mathrm{~g}\left(\mathrm{NH}_{4}\right) \mathrm{Mo}_{7} \mathrm{O}_{24^{-}}\right.$ $4 \mathrm{H}_{2} \mathrm{O}$ in $84 \mathrm{mLs}$ deionized water and $16 \mathrm{mLs} 0.36 \mathrm{~N} \mathrm{H}_{2} \mathrm{SO}_{4}$ ) and $2.0 \mathrm{~mL}$ malachite green solutions ( $1.11 \mathrm{~g}$ polyvinyl alcohol and $0.11 \mathrm{~g}$ malachite green in $1 \mathrm{~L}$ deionized water) and decanted into a cuvette where absorbance was recorded at $610 \mathrm{~nm}$ by a Spectronic GENESYS 20 spectrophotometer. The phosphate content of each sample was related to cell mass per gram dry weight aquifer material, and was obtained using the average of a range of conversion factors reported by 
Dobbs and Findlay [1993] $\left(3.4 \times 10^{7}\right.$ to $2.0 \times 10^{9}$ cells $/ \mathrm{nmol}$ $\mathrm{PO}_{4}$ ).

[8] To estimate total lipid biomass levels after the inoculation phase but before the biostimulation phase, duplicate columns constructed from $1.27 \mathrm{~cm}$ vinyl tubing were wet packed with deionized water and the same sterilized sand used in the sandbox experiment. A total of $20 \mathrm{~L}$ of groundwater collected from the same well used in the sandbox experiment was fed through each column using a Mariotte assembly for a period of seven days. After seven days, columns were freeze-dried and analyzed for total lipid biomass. Sterilized sand was also analyzed for total lipid biomass to ensure sterility of the material.

[9] Sand representing depths 10-20 cm from core samples, along with a subset of sterilized sand, was powdered and analyzed by X-ray powder diffraction (XRD) on a Bruker AXS D8 Advance X-ray diffractometer equipped with a xyz stage, and a $\mathrm{Cu}-\mathrm{Ks}$ beam to characterize the bulk mineralogy. A subset of powdered samples from the above mentioned core locations were also analyzed in duplicate for total inorganic carbon concentration to quantify the fraction of carbonate minerals within the sand using a UIC Coulometrics TC/TIC/TOC carbon analyzer with CM5230 acidification module and $\mathrm{CM} 5015 \mathrm{CO}_{2}$ coulometer.

\subsection{Ground-Penetrating Radar Data Acquisition and Analysis}

[10] Ground-penetrating radar with $1200 \mathrm{MHz}$ antennas (Sensors \& Software Inc. pulseEKKO 1000) was employed to examine porous medium changes over time in response to biostimulation. Ground-penetrating radar data were acquired by transmitting through the front side of the sandbox and receiving the energy reflected by the aluminum reflector at the back side of the sandbox. The metallic reflector returns nearly all the GPR energy from the back wall of the reactor. In this setup, the EM energy travels through the saturated porous medium twice, simulating the effect of a longer travel path, and enhancing potential arrival time and amplitude signal changes. Ground-penetrating radar data were acquired twice daily through the saturated sand at 21 upgradient, and 21 downgradient grid locations as well as through the open air portion of the polycarbonate box (at the top) (Figure 1). EM wave transmission through air was used to monitor instrument response during the 90-day experiment. On the days of active biostimulation, GPR data were acquired prior to the addition of growth nutrient. Eight radar pulses were transmitted and summed (stacked) for each recorded trace, using a $25 \mathrm{~ns}$ time window and $0.01 \mathrm{~ns}$ sample interval with no gain. Reflected signal two-way travel times were determined by the time difference between the maximum amplitude of the direct air-wave arrival and the first break of the reflected wave. Two-way travel time and maximum amplitude of the reflected signals were determined for analysis.

[11] Dielectric properties of the medium, as well as GPR instrument response, can vary temporally as a function of ambient temperature, and instrument timing drift (time zero drift). Generally, those sources of arrival time change are considered negligible in typical GPR field investigations. However, to investigate the effects of biostimulation in this experiment, arrival time changes accurate to within a fraction of a nanosecond needed to be assessed. The design of the experiment allowed the determination of daily relative chan- ges between baseline observations (upgradient) and biostimulated sand (downgradient). Comparison between upgradient and downgradient GPR measurements, which were similarly affected by any temperature variations, ensured that observed changes in radar signals could be distinguished from simple temperature effects.

[12] The GPR observations were examined in two ways. First, a comparison was made of the ( 21 grid point) average daily responses from each of the upgradient and downgradient sections of the sandbox. Differences in two-way travel times and maximum amplitudes were used to examine relative changes between the two sides of the tank. Examining travel time data in this fashion has the advantage of removing the effects of instrument drift, and water's dielectric constant dependence to temperature. Next, in order to compare spatial variations within the sandbox over the 90-day experiment, the mean upgradient two-way travel time $(9.06 \mathrm{~ns})$ was used as a baseline to calculate the calibration needed to remove the effects of daily instrument drift and temperature. Two-way travel times for each one of the 42 GPR monitoring grid points were computed for the 90-day experiment in this fashion. The local variations in box geometry, such as bulging in the center due to packing, were corrected by subtracting the background (each grid point's mean twoway travel time for prebiostimulation days 22-40) from each grid point's respective two-way travel time.

\section{Results}

[13] The sandbox was monitored during an initial 20-day equilibration phase when groundwater from the Kansas River aquifer was flushed through the reactor, replacing the initial (deionized) pore water. Background data were collected for an additional 20 days to establish and record prebiostimulation upgradient and downgradient conditions. The experiment then proceeded with 20 days of weekly nutrient additions followed by 30 days of twice weekly nutrient additions.

\subsection{Electrical Conductivity and $\mathbf{p H}$}

[14] Water samples were collected daily from the monitors in the upgradient and downgradient sides of the sandbox. Pore water temperature (Figure 2a), electrical conductivity (Figure $2 \mathrm{~b}$ ) and $\mathrm{pH}$ (Figure 2c) were monitored in the saturated sand over time. Data prior to day 20 are considered unrepresentative of background since during this time the initial pore water was being replaced with groundwater. By days $22-40, \mathrm{pH}$ and EC had achieved steady baselines. Pore water EC, downgradient of the nutrient injection wells, continuously increased after biostimulation (day 41), due in part to the nutrient solutions themselves. Immediately prior to biostimulation, both upgradient and downgradient $\mathrm{pHs}$ were roughly 7.4. As biostimulation progressed, $\mathrm{pH}$ became more variable, but remained similar in magnitude in both ends of the tank.

\subsection{Changes in Daily Average GPR Two-Way Travel Times and Maximum Amplitudes}

[15] Daily average changes in two-way travel times between the downgradient and upgradient portions of the tank were evaluated by plotting the difference in the daily means of the downgradient values from the upgradient values (Figure 2d). Prior to biostimulation (days 22-40), a weak upward trend 

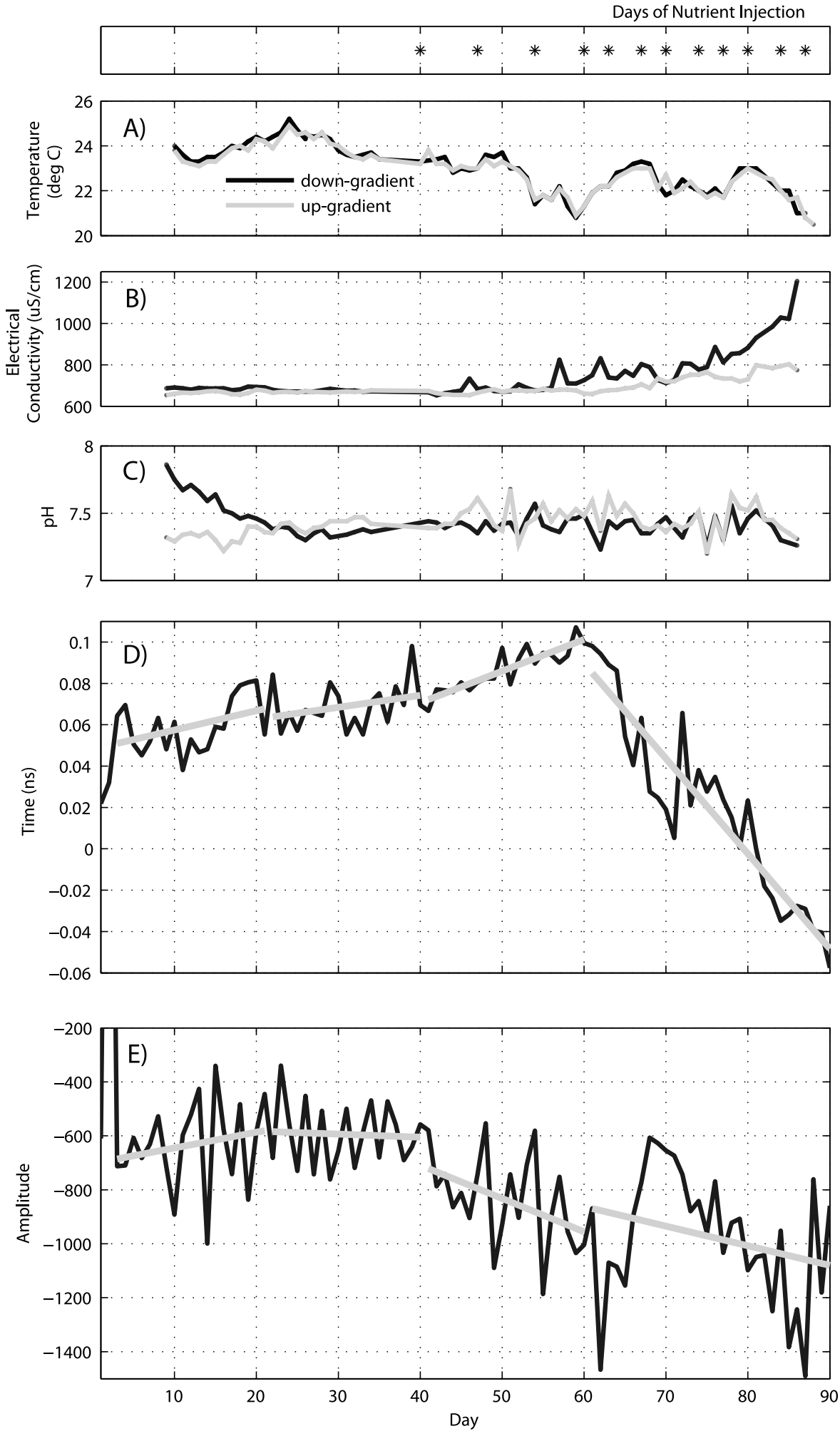

Figure 2. Comparison of upgradient and downgradient (a) pore water temperature, (b) pore water electrical conductivity, (c) $\mathrm{pH}$, (d) differences in mean two-way travel time (downgradient minus upgradient), and (e) differences in mean maximum amplitude (downgradient minus upgradient). Initial biostimulation with weekly nutrient additions began on day 40 , whereas twice weekly nutrient additions began on day 60, as shown above plot A. Trends lines (gray) in Figures $2 \mathrm{~d}$ and $2 \mathrm{e}$ are fitted to data during the reactor's equilibration phase ( $<$ day 21 ), background phase (days $22-40$ ), weekly biostimulation phase (days 41-60), and twice weekly biostimulation phase (days 61-90). 


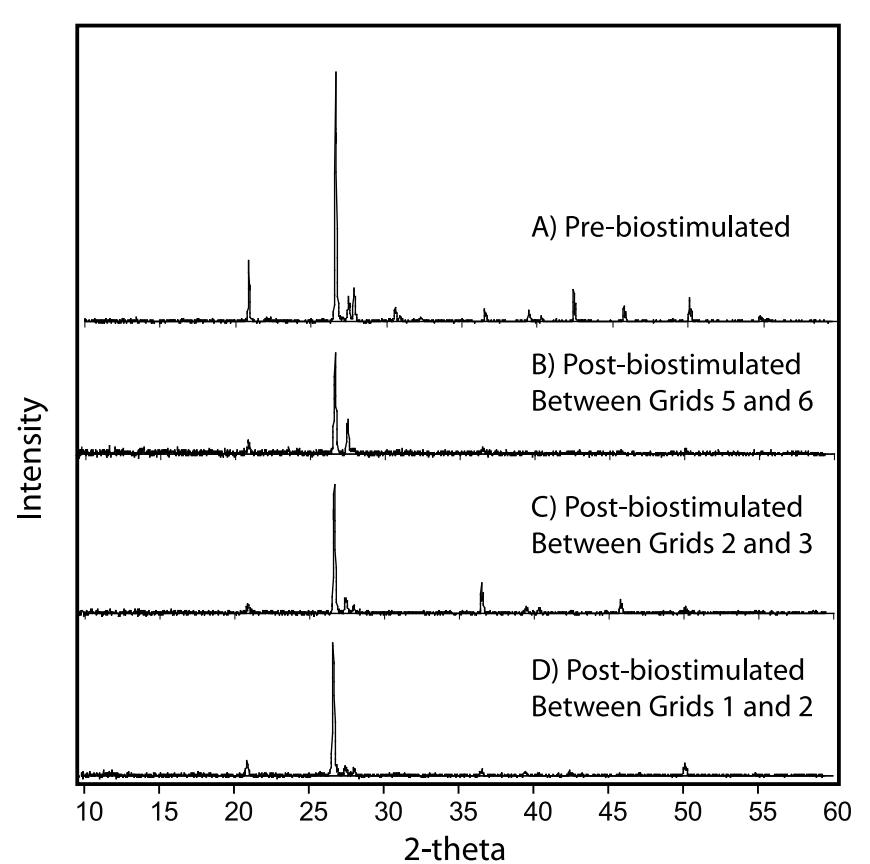

Figure 3. Powder XRD patterns of sand used in the experiment (a) prior to being packed into the sandbox, and (b) from core located between grids 5 and 6, (c) grids 2 and 3, and (d) grids 1 and 2. All samples from the core represent depths of 10-20 $\mathrm{cm}$ below the sand surface. All observed peaks of 2-theta greater than $35^{\circ}$ are interpreted as secondary quartz peaks.

in the data exists, with a slope of 0.00058 (Figure 2d). After beginning the weekly addition of nutrients (days 41-60), the fitted trend line slope doubles to 0.0015 (Figure 2d). This resulted from the mean downgradient two-way travel time increasing relative to that associated with the upgradient end of the tank. Increased nutrient loading (twice per week) after day 60, coincided with the observed formation of gas bubbles in the downgradient portion of the box and a sharp decrease in downgradient GPR arrival times. These occurrences are marked by a reversal in trend line slope in Figure $2 \mathrm{~d}$ (slope $=-0.0046)$.

[16] Amplitude observations exhibit greater variability than arrival time observations. The difference in the daily average GPR maximum amplitude between the downgradient and upgradient sides of the tank indicate a generally decreasing trend, beginning at approximately day 40, which correlates to the rise in electrical conductivity (section 3.1) and the onset of nutrient delivery (Figures $2 \mathrm{~b}$ and $2 \mathrm{e}$ ).

\subsection{Sediment Mineralogy}

[17] To examine changes in bulk sediment mineralogy, postbiostimulated sediment samples collected from core on day 90 were analyzed by XRD and compared to prebiostimulated sediments. Both prebiostimulated and postbiostimulated XRD patterns exhibited mineralogy dominated by quartz and anorthoclase (e.g., $(\mathrm{Na}, \mathrm{K}) \mathrm{AlSi}_{3} \mathrm{O}_{8}$; Figure 3 ). Ordered quartz peaks were observed at 2-theta angles of $20.87^{\circ}$ and $26.63^{\circ}$ as well as peaks observed above $35^{\circ}$. A doublet peak at 2-theta angles of $27.48^{\circ}$ and $27.85^{\circ}$ is con- sistent with anorthoclase. A small peak that was present only in the prebiostimulated sediment sample, at a 2-theta angle of $30.57^{\circ}$, could not be uniquely identified. Because it did not correspond to peaks from any of the common minerals or a readily soluble phase, it was treated as an anomalous substance present in unrepresentative amounts in the prebiostimulated sand sample. Further work is needed to identify the peak conclusively. Any other minerals in the samples were present in insufficient quantities to identify or detect with the instrument. Powdered sediments from the same core locations used in the XRD analysis were analyzed to determine the fraction of inorganic carbon. Duplicate samples from prebiostimulated and postbiostimulated sediments each comprised an average of $0.007 \%$ ( $\pm 0.001 \%$ and $\pm 0.004 \%$, respectively) carbonate by mass.

[18] Following the addition of the nutrient solution to the tank water, a black precipitate was observed at the downgradient end of the tank. Although visible on the sediment that was cored, this precipitate was not identifiable by XRD. This may have been due to insufficient coating thicknesses on the grains, or an amorphous structure of the precipitate. Given the reducing conditions of the experiment, it is likely that dissimilatory iron and sulfate reduction were occurring concomitantly [Jakobsen et al., 1998]. This would be expected to result in the subsequent rapid precipitation of amorphous iron sulfides [Rickard, 1995]. The formation of the black precipitate is consistent with this expectation. Further support comes from the observation that the precipitate converted to a rust colored solid (probably an iron oxide or oxyhydroxide) when it was allowed to oxidize at the end of the experiment.

\subsection{Changes in Total Lipid Biomass}

[19] Initial biomass of the sterilized sand was found to be below the detection limit of the method $\left(<10^{4}\right.$ cells $\mathrm{g}^{-1}$ dry weight sediment). Column experiments representing biomass levels after the inoculation phase but before the biostimulation phase were between $10^{7}$ and $10^{8}$ cells $\mathrm{g}^{-1}$ dry weight sediment. After inoculation and 50 days of growth nutrient application (day 90), biomass increased to $10^{8}$ $10^{9}$ cells $\mathrm{g}^{-1}$ dry weight sediment in both downgradient and upgradient locations within the sandbox (Figure 4).

\subsection{Spatial Changes of GPR Arrival Times}

[20] Spatial changes in GPR two-way travel time from background (where background was again considered the mean of travel times between days 22 and 40) at each of the 42 grid locations were compared against the corresponding averages of days 28-32, reflecting times of no change, days 58-62 and days 88-90, corresponding to times of maximum change between upgradient and downgradient sandbox conditions (Figure 5). Specifically, days 58-62 showed an increase in two-way travel time difference (more negative) downgradient from the nutrient supply wells. Days $88-90$ coincide with the appearance of gas bubbles at the base of the tank, downgradient of the nutrient release wells. Twoway travel times were noted to decrease (more positive) in this area, consistent with gas formation. About this same time, two-way travel times began to increase in the upgradient end of the tank, above $45 \mathrm{~cm}$ depth, suggesting a spreading of the effects of nutrient injection to that area (Figure 5). Gas 


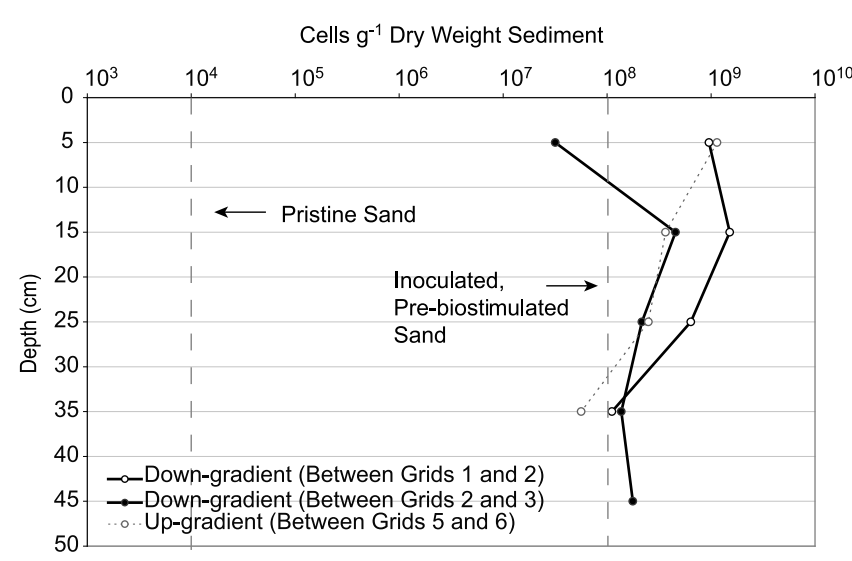

Figure 4. Average biomass measured in the sand used in the experiment. Prebiostimulation conditions, shown as vertical dashed lines, were determined in samples not from the sandbox, but handled identically to those collected from the sandbox. Samples of postbiostimulation sand from the upgradient end of the sand box, at the end of the experiment, are shown as points connected with a dotted line, and downgradient samples are shown as points connected by solid lines. Note that by the end of the experiment, nutrient additions had affected both sides of the sandbox.

bubbles were not observed in the upgradient portion of the tank.

\section{Discussion}

[21] The $\mathrm{pH}$ and electrical conductivity data were used to help assess changes in the sandbox due to increased microbial activity, and to help interpret changes in GPR data. Fluctuations in pore water temperature were a result of changes in air temperature within the building. Such changes would likely affect the growth rate of bacteria to some degree, but the outcome would be increased biomass, regardless. Early time variations in the $\mathrm{pH}$ are thought to be due to replacement of the original pore water with groundwater, and equilibration of the groundwater with the porous medium. The $\mathrm{pH}$ data set was collected in part to serve as an indicator of microbial metabolism (i.e., production of $\mathrm{CO}_{2}$ ) and water-rock interaction. However, after the first 21 days of the experiment, the variability of $\mathrm{pH}$ over time was never greater than $0.25 \mathrm{pH}$ units. This relatively small $\mathrm{pH}$ variation throughout prebiostimulation and postbiostimulation times indicates either that enhanced microbial growth did not affect the $\mathrm{pH}$ of the system greatly, or that the pore water was adequately buffered to mask the effects. As no potential buffers existed in the sediment mineralogy, as evidenced by XRD analysis, we hypothesize that the solution was buffered by TSB (manufacturer specified set point $\mathrm{pH}$ of 7.3).

[22] The injection of dissolved carbon and nutrients increased the electrical conductivity of the groundwater and this was expected to attenuate the radar signal amplitude. Furthermore, metabolic products of biological activity have been shown to increase electrical conductivity through mineral weathering and cause attenuation of radar waves [Sauck et al., 1998]. In fact, the signal was attenuated by a mean of $18 \%$ during the entire period of biostimulation (days 40-90) in the downgradient portion of the sandbox, confirming the GPR's amplitude responsiveness to changes in bulk electrical conductivity. However, it is not possible with the current experimental design to differentiate the competing mechanisms of radar signal attenuation.

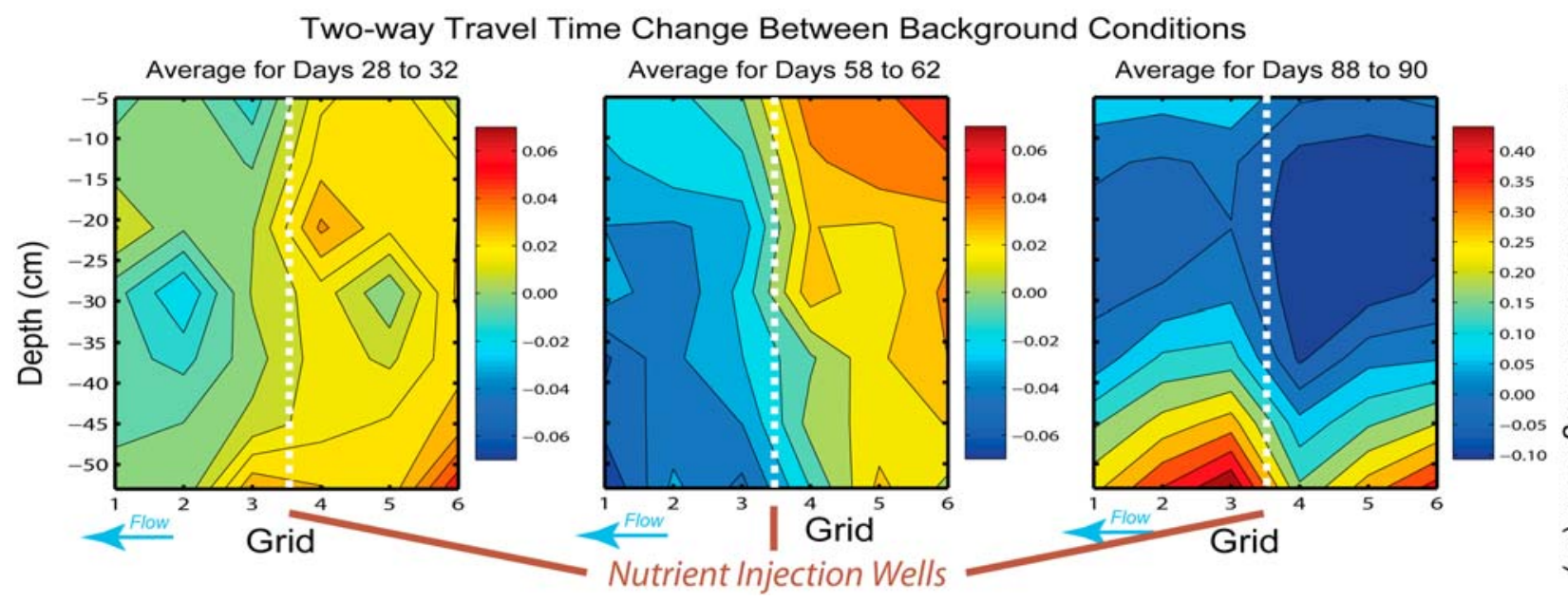

Figure 5. Side panel view of the sandbox showing spatial changes in two-way travel times (i.e., average background travel time minus measured travel times, in nanoseconds) for (left) days 28-32, (middle) days 58-62, and (right) days 88-90. Cooler colors indicate negative changes corresponding to increased twoway travel times, whereas warmer colors indicate positive changes associated with decreased two-way travel times. The location of the nutrient injection wells is shown by the vertical white dashed lines. Note the decrease in two-way travel time change downgradient of the nutrient injection wells on days 58-62, following biostimulation, and the increase in two-way travel time change relative to the background downgradient of the nutrient injection wells on days 88-90. Note also that an expanded color scale is used for days 88-90. 
[23] Biomass measured from core sediments was shown to vary over 1.5 orders of magnitude from sample to sample. This high degree of biomass variability between depthspecific samples is not surprising since only $10 \mathrm{~g}$ of sediment was homogenized for lipid biomass analysis, therefore spatial variability was unavoidable. Nevertheless, the total biomass observed after biostimulation was about one order of magnitude greater than the inferred biomass before biostimulation (after inoculation) (Figure 4). Using the same method of biomass enumeration, Schillig et al. [2010] reported similar total biomass magnitudes $\left(10^{9}\right.$ cells $\mathrm{g}^{-1}$ dry weight sediment) and changes (one order of magnitude) as a result of adding dissolved oxygen to a petroleum contaminated aquifer. In that case, localized decreases in groundwater velocity and flow redirection resulted from the biomass growth. Other studies have shown similar behaviors, albeit under very different experimental conditions. For example, in laboratory tests an $80-90 \%$ decrease in hydraulic conductivity was observed with an increase in biomass of one order of magnitude leading to a final concentration of $10^{8}-10^{9}$ cells $\mathrm{g}^{-1}$ dry weight sediment [Vandevivere and Baveye, 1992b; Holm, 2001].

[24] Following the change to twice weekly nutrient injections, it is likely that the accumulation of biomass and production of gas downgradient of the nutrient injection wells both contributed to decreases in the hydraulic conductivity of the porous medium. This may have resulted in nutrient delivery into the upgradient portion of the sandbox late in the experiment. Evidence for upgradient nutrient delivery and biostimulation is shown in Figure 2c where the upgradient pore water electrical conductivity begins to increase from baseline after day 60 . By day 88 , two-way travel times were noted to increase by $0.1 \mathrm{~ns}$ relative to the background in the upgradient portion of the sandbox (Figure 5, right).

[25] Increasing two-way travel times observed after biostimulation indicate an increasing bulk dielectric constant of the porous medium, which could be caused by either an increased porosity due to dissolution of mineral grains and/or possibly an increase in biomass. Changes in dielectric constant reported by Hubbard et al. [2008] were attributed to the dissolution of calcite minerals near the injection well and further downgradient precipitation. Data reported by McGlashan [2007] at a petroleum contaminated aquifer indicated that the bulk dielectric constant increased as a result of biostimulation. One of the mechanisms postulated by McGlashan [2007] to cause the increase in the bulk dielectric constant was an increase in saturated porosity by $1-3 \%$ (i.e., from an initial value of 0.38 to 0.41 ) through mineral dissolution. This increase from 1 to $3 \%$ in saturated porosity assumes the dielectric constant of biomass is equal to that of water. To estimate the change in porosity required to explain the travel time changes observed in this study, the two-way travel times were corrected for the thickness of the polycarbonate, and converted to bulk dielectric constants by:

$$
\varepsilon_{m}=\left(\frac{c t}{x}\right)^{2}
$$

where $\varepsilon_{m}$ is the bulk dielectric constant, $c$ is propagation velocity of electromagnetic waves in free space $\left(0.3 \mathrm{~m} \mathrm{~ns}^{-1}\right)$, $t$ is the two-way travel time corrected for the time required to propagate EM energy four times through $0.0127 \mathrm{~m}$ thick polycarbonate with a dielectric constant of 3 , and $x$ is the total travel distance $(0.6 \mathrm{~m})$. Finally, $\varepsilon_{m}$ was converted into a volumetric water content or saturated porosity $\left(\theta_{v}\right)$ using the equation by Topp et al. [1980]:

$$
\begin{aligned}
\theta_{v}= & -5.3 \times 10^{-2}+2.92 \times 10^{-2}\left(\varepsilon_{m}\right)-5.5 \times 10^{-4}\left(\varepsilon_{m}^{2}\right) \\
& +4.3 \times 10^{-6}\left(\varepsilon_{m}^{3}\right)
\end{aligned}
$$

Two-way travel time increases, using both raw and driftcorrected data, can be explained by a total porosity increase of less than $1 \%$ (i.e., 0.340 to 0.349 ), which is below the standard error of the method ( 0.013 or $1.3 \%)$. Even so, the negligible presence of carbonate or other soluble minerals in the porous medium, and the circum-neutral $\mathrm{pH}$ that persisted throughout the experiment, argue against mineral dissolution as a cause of the observed travel time changes. Thus, the growth of biomass can be considered as a possible cause of the radar wave velocity changes.

[26] By assuming a constant porosity, an increase in twoway travel time from biomass accumulation would suggest that the biomass had a bulk dielectric constant (at $1200 \mathrm{MHz}$ frequency) that was greater than that of the pore water. There is little in the literature to support this hypothesis presently. However, the idea is consistent with the findings of Zhang and Van Geel [2007] who reported dielectric constants greater than expected when they made TDR measurements in peat biofilters. They attributed their results to the growth of bacteria.

[27] The rapid decrease in two-way travel time observed after day 60 (Figures 2d and 5) was coincident with the observation of gas bubbles accumulating on the downgradient side of the tank. The total change in saturation caused by gas bubble accumulation was estimated using the complex refractive index method (CRIM), a dielectric mixing formula that relates changes in bulk dielectric constant to changes in air, soil, or water content [Wharton et al., 1980]:

$$
\sqrt{\varepsilon_{m}}=\theta_{v} S_{w} \sqrt{\varepsilon_{w}}+\left(1-\theta_{v}\right) \sqrt{\varepsilon_{s}}+\theta_{v}\left(1-S_{w}\right) \sqrt{\varepsilon_{a}}
$$

where $\varepsilon_{m}$ is the observed bulk dielectric constant calculated from equation (1), $\varepsilon_{w}$ is the temperature dependent dielectric constant of water according to Wraith and $\operatorname{Or}$ [1999], $\varepsilon_{s}$ is the dielectric constant of dry geologic material, $\varepsilon_{a}$ is the dielectric constant of air $\left(\varepsilon_{a}=1\right)$, and $S_{w}$ is water saturation. The average porosity of the sandbox, prior to biostimulation, was estimated to be 0.34 using equation (2) for data collected on day 32. The dielectric constant of the dry silica sand was calculated to be 4.53 by calibrating $\varepsilon_{m}$ from day 32 with equations (2) and (3). By using equation (3), and assuming no change in total porosity, the maximum decrease in saturation observed on day 88 (gridline $3,50 \mathrm{~cm}$ below the surface in Figure 5), compared to background conditions on day 32 , was $7.5 \%$. Therefore, $7.5 \%$ of the pore volume occupied by gas (i.e., saturated porosity changes from 0.340 to 0.265 ) could explain the GPR response.

[28] The changes observed in two-way travel time in this study were small in magnitude, though consistent in nature. Two-way travel times measured in zones receiving nutrients were shown to increase slightly relative to background, as depicted by the increasing slope in Figure 2d, representative of days 41-60. These changes are relative differences between downgradient and upgradient average measurements and are free of water temperature or instrument drift 
caused variations. Furthermore, by doubling the weekly nutrient delivery on day 60 , another measurable change in slope (negative) occurred which was explainable from direct observations (appearance of bubbles) and theoretical calculations (Figure 2d). Temporal changes in mean EM propagation velocity from background conditions (days 22-40) were determined by dividing the known travel distance by the upgradient or downgradient mean two-way travel time. Between days 41 and 60, mean velocity decreased relative to background by $0.23 \%\left(0.001 \mathrm{~m} \mathrm{~ns}^{-1}\right)$ in downgradient locations, whereas upgradient locations decreased by less than $0.04 \%\left(0.00003 \mathrm{~m} \mathrm{~ns}^{-1}\right)$. Between days 61 and 90 , mean velocity increased relative to background by $0.54 \%$ $\left(0.004 \mathrm{~m} \mathrm{~ns}^{-1}\right)$ in downgradient locations, whereas mean velocity of upgradient locations remained unchanged from days 41 to 60 . By applying the mean two-way travel times described above to equation (1), average changes in $\varepsilon_{m}$ can also be calculated for the experiment. Background conditions representing days 22-40 were calculated to have a mean $\varepsilon_{m}$ of 19.43 and 19.13 for downgradient and upgradient locations, respectively. Between days 41 and 60 , mean $\varepsilon_{m}$ increased to 19.53 in downgradient locations, whereas upgradient locations increased to 19.14. Between days 61 and 90 , mean $\varepsilon_{m}$ decreased to 19.22 in downgradient locations, while upgradient location mean $\varepsilon_{m}$ remained unchanged from days 41 to 60 . Downgradient $\varepsilon_{m}$ decrease coincides with the visual observation of gas bubbles in the sandbox. The computed $\varepsilon_{m}$ increase is consistent with dielectric spectroscopy studies conducted in the frequency range of GPR where only small increases in dielectric constant relative to the suspending fluid were measured [Carstensen, 1967; Asami et al., 1980]. However, in order to calculate the dielectric constant of bacteria using GPR in this experiment, further study would be needed to determine the portion of the pore space occupied by the biomass itself.

\section{Conclusions and Implications}

[29] Daily changes in GPR two-way travel times were observed in this study as a result of enhanced biostimulation. From this it is concluded that stimulated microbial activity can produce small, but measurable effects on the bulk dielectric properties in saturated silicate sands. Relative decreases in GPR signal two-way travel time and increases in attenuation observed at the end of the experiment were coincident with the observed formation of biogenic gas bubbles. However, earlier increases in two-way travel time and attenuation were also observed in this study, apparently the direct result of biostimulation. Given the $\mathrm{pH}$ conditions observed in the experiment and the mineralogical composition of the sand, mineral dissolution to the extent required to alter two-way travel time is thought to be unlikely over the duration of the experiment. It is suggested here that an alternative explanation, directly related to the presence of biomass, exists to account for the increase in two-way travel time reported in this study.

[30] From the above, the results of this study indicate that GPR is sensitive to porous medium changes indirectly, and possibly directly, related to the biostimulation of sand-sized granular porous media. The changes that were detected correspond to biomass concentrations that may be sufficient to alter groundwater flow, and may therefore be of practical concern. By furthering our understanding of the petrophysical changes that occur during biostimulation in controlled environments, the ability to detect and correctly interpret biological transformations and processes in the subsurface with GPR can be better developed for field-scale applications. However, further research is needed to ascertain the mechanistic cause for the changes observed in GPR signals.

[31] Acknowledgments. Funding for this project was through the National Science Foundation CAREER grant 0134545 awarded to J.F. Devlin and NSF EAR/IF-0345445 for acquisition of GPR instrumentation awarded to G. Tsoflias. The opinions, findings, and recommendations of this study are the views the author(s) and do not necessarily reflect the views and opinions of the National Science Foundation. We would like to thank Mike McGlashan, Kwan Yee Cheng, Kelly Peterson, Lindsay Mayer, and Breanna Huff for assistance with this project. We also thank two anonymous reviewers for their helpful comments that led to the improvement of this manuscript.

\section{References}

Abdel Aal, G. Z., L. D. Slater, and E. A. Atekwana (2006), Inducedpolarization measurements on unconsolidated sediments from a site of active hydrocarbon biodegradation, Geophysics, 71(2), H13-H24.

Abdel Aal, G., E. A. Atekwana, S. Radzikowski, and S. Rossbach (2009), Effect of bacterial adsorption on low frequency electrical properties of clean quartz sands and iron-oxide coated sands, Geophys. Res. Lett., 36, L04403, doi:10.1029/2008GL036196.

Asami, K., T. Hanai, and N. Koizumi (1980), Dielectric analysis of Escherichia-Coli suspensions in the light of the theory of interfacial polarization, Biophys. J., 31(2), 215-228.

Atekwana, E. A., R. S. Rowe, D. D. Werkema, and F. D. Legall (2004a), The relationship of total dissolved solids measurements to bulk electrical conductivity in an aquifer contaminated with hydrocarbon, J. Appl. Geophys., 56(4), 281-294.

Atekwana, E. A., D. D. Werkema, J. W. Duris, S. Rossbach, W. A. Sauck, D. P. Cassidy, J. Means, and F. D. Legall (2004b), In-situ apparent conductivity measurements and microbial population distribution at a hydrocarboncontaminated site, Geophysics, 69(1), 56-63.

Baveye, P., P. Vandevivere, B. L. Hoyle, P. C. DeLeo, and D. S. de Lozada (1998), Environmental impact and mechanisms of the biological clogging of saturated soils and aquifer materials, Crit. Rev. Environ. Sci. Technol., 28(2), 123-191.

Bone, S., B. Z. Ginzburg, H. Morgan, G. Wilson, and B. Zaba (1996), Time-domain reflectometry studies on Halobacterium halobium and Halobacterium marismortui, Phys. Med. Biol., 41(1), 45-54.

Bradford, J. H. (2007), Frequency-dependent attenuation analysis of ground-penetrating radar data, Geophysics, 72(3), J7-J16.

Carstensen, E. (1967), Passive electrical properties of microorganisms. 2. Resistance of bacterial membrane, Biophys. J., 7(5), 493-503.

Cassidy, D. P., D. D. Werkema, W. Sauck, E. Atekwana, S. Rossbach, and J. Duris (2001), The effects of LNAPL biodegradation products on electrical conductivity measurements, J. Environ. Eng. Geophys., 6(1), 47-52.

Cassidy, N. J. (2007), Evaluating LNAPL contamination using GPR signal attenuation analysis and dielectric property measurements: Practical implications for hydrological studies, J. Contam. Hydrol., 94(1-2), 49-75.

Che-Alota, V., E. A. Atekwana, E. A. Atekwana, W. A. Sauk, and D. D. Werkema (2009), Temporal geophysical signatures from contaminantmass remediation, Geophysics, 74(4), B113-B123.

Comas, X., L. Slater, and A. Reeve (2005), Spatial variability in biogenic gas accumulations in peat soils is revealed by ground penetrating radar (GPR), Geophys. Res. Lett., 32, L08401, doi:10.1029/2004GL022297.

DeJong, J. T., M. B. Fritzges, and K. Nüsslein (2006), Microbially induced cementation to control sand response to undrained shear, J. Geotech. Geoenviron. Eng., 132(11), 1381-1392.

Delozada, D. S., P. Vandevivere, P. Baveye, and S. Zinder (1994), Decrease of the hydraulic conductivity of sand columns by Methanosarcina-barkeri, World J. Microbiol. Biotechnol., 10(3), 325-333.

Devlin, J. F., and J. F. Barker (1996), Field investigation of nutrient pulse mixing in an in situ biostimulation experiment, Water Resour. Res., 32(9), 2869-2877.

Dobbs, F. C., and R. H. Findlay (1993), Analysis of microbial lipids to determine biomass and detect the response of sedimentary microorganisms to disturbance, in Handbook of Methods in Aquatic Microbial Ecology, edited by P. F. Kemp et al., pp. 347-358, Lewis, Boca Raton, Fla. 
Gierczak, R. F. D., J. F. Devlin, and D. L. Rudolph (2007), Field test of a cross-injection scheme for stimulating in situ denitrification near a municipal water supply well, J. Contam. Hydrol., 89(1-2), 48-70.

Holm, J. (2001), Effect of biomass growth on the hydrodynamic properties of groundwater aquifers, series paper, 72 pp., Dep. of Hydrodyn. and Water Resour., Tech. Univ. of Denmark, Lyngby.

Hubbard, S. S., K. Williams, M. E. Conrad, B. Faybishenko, J. Peterson, J. Chen, P. Long, and T. Hazen (2008), Geophysical monitoring of hydrological and biogeochemical transformations associated with $\mathrm{Cr}(\mathrm{VI})$ bioremediation, Environ. Sci. Technol., 42(10), 3757-3765.

Jakobsen, R., H.-J. Albrechtsen, M. Rasmussen, H. Bay, P. L. Bjerg, and T. H. Christensen (1998), H2 concentrations in a landfill leachate plume (Grindsted, Denmark): In situ energetics of terminal electron acceptor processes, Environ. Sci. Technol., 32(14), 2142-2148.

Lane, J. W., F. D. Day-Lewis, and C. C. Casey (2006), Geophysical monitoring of a field-scale biostimulation pilot project, Ground Water, 44(3), 430-443.

McElwee, C. D., et al. (1995), Characterization of heterogeneities controlling transport and fate of pollutants in unconsolidated sand and grave aquifers, final report, Kans. Geol. Surv. Open File Rep., 95-16, 559 pp.

McGlashan, M. A. (2007), Monitoring dielectric property changes and groundwater velocity changes in a contaminated aquifer using borehole ground penetrating radar and multi-level point velocity probes (PVPs), M.S. thesis, 148 pp., Univ. of Kans., Lawrence.

McVey, S. (2000), Geomicrobial denitrifying and nitrifying characteristics of a nitrate-contaminated alluvial aquifer, northeastern Kansas, M.S. thesis 116 pp, Univ. of Kans., Lawrence.

Miller, J. H., D. Nawarathna, D. Warmflash, F. A. Pereira, and W. E. Brownell (2005), Dielectric properties of yeast cells expressed with the motor protein prestin, J. Biol. Phys., 31(3-4), 465-475.

Ntarlagiannis, D., N. Yee, and L. Slater (2005), On the low-frequency electrical polarization of bacterial cells in sands, Geophys. Res. Lett., 32, L24402, doi:10.1029/2005GL024751.

Patel, P., and G. H. Markx (2008), Dielectric measurement of cell death, Enzyme Microb. Technol., 43(7), 463-470.

Prodan, C., F. Mayo, J. R. Claycomb, J. H. Miller, and M. J. Benedik (2004), Low-frequency, low-field dielectric spectroscopy of living cell suspensions, J. Appl. Phys., 95(7), 3754-3756.

Rickard, D. (1995), Kinetics of FeS precipitation: Part 1. Competing reaction mechanisms, Geochim. Cosmochim. Acta, 59(21), 4367-4379.

Rinck-Pfeiffer, S., S. Ragusa, P. Sztajnbok, and T. Vandevelde (2000), Interrelationships between biological, chemical, and physical processes as an analog to clogging in aquifer storage and recovery (ASR) wells, Water Res., 34(7), 2110-2118.
Sanchis, A., A. P. Brown, M. Sancho, G. Martinez, J. L. Sebastian, S. Munoz, and J. M. Miranda (2007), Dielectric characterization of bacterial cells using dielectrophoresis, Bioelectromagnetics, 28(5), 393-401.

Sauck, W. A. (2000), A model for the resistivity structure of LNAPL plumes and their environs in sandy sediments, J. Appl. Geophys., 44(2-3), 151-165. Sauck, W. A., E. A. Atekwana, and M. S. Nash (1998), High conductivities associated with an LNAPL plume imaged by integrated geophysical techniques, J. Environ. Eng. Geophys., 2(3), 203-212.

Schillig, P. C., J. F. Devlin, J. A. Roberts, G. P. Tsoflias, and M. A. McGlashan (2010), Transient heterogeneity in an aquifer undergoing bioremediation of hydrocarbons, Ground Water, 9999, doi:10.1111/j.1745-6584.2010. 00682.x.

Topp, G. C., J. L. Davis, and A. P. Annan (1980), Electromagnetic determination of soil water content: Measurements in coaxial transmissionlines, Water Resour. Res., 16(3), 574-582.

Vandevivere, P., and P. Baveye (1992a), Effect of bacterial extracellular polymers on the saturated hydraulic conductivity of sand columns, Appl. Environ. Microbiol., 58(5), 1690-1698.

Vandevivere, P., and P. Baveye (1992b), Saturated hydraulic conductivity reduction caused by aerobic-bacteria in sand columns, Soil Sci. Soc. Am. J., 56(1), 1-13.

Welch, S. A., A. E. Taunton, and J. F. Banfield (2002), Effect of microorganisms and microbial metabolites on apatite dissolution, Geomicrobiol. J., 19(3), 343-367.

Wharton, R. P., G. A. Hazen, R. N. Rau, and D. L. Best (1980), Electromagnetic propagation logging: Advances in technique and interpretation, paper presented at 55th Annual Fall Technical Conference and Exhibition, Soc. of Pet. Eng., Dallas, Tex.

Williams, K. H., D. Ntarlagiannis, L. D. Slater, A. Dohnalkova, S. S. Hubbard, and J. F. Banfield (2005), Geophysical imaging of stimulated microbial biomineralization, Environ. Sci. Technol., 39(19), 7592-7600.

Wraith, J. M., and D. Or (1999), Temperature effects on soil bulk dielectric permittivity measured by time domain reflectometry: Experimental evidence and hypothesis development, Water Resour. Res., 35(2), 361-369.

Zhang, X. Y., and P. J. Van Geel (2007), Development of a vertical TDR probe to evaluate the vertical moisture profile in peat columns to assess biological clogging, J. Environ. Eng. Sci., 6(6), 629-642.

J. F. Devlin, E. M. Patterson, J. A. Roberts, P. C. Schillig, and G. P. Tsoflias, Department of Geology, University of Kansas, Lawrence, KS 66045, USA. (schillig@ku.edu) 